Silva Flores, Viviana.

Artista Visual. Alumna Doctorado en Bellas Artes Universidad Complutense de Madrid. Sección Departamental de Historia del Arte III.

\title{
Práctica artística como Investigación: Aproximaciones a un debate.
}

\author{
TIPO DE TRABAJO
}

Comunicación.

PALABRAS CLAVE

Investigación, práctica artística, tesis doctoral, mostrar, conocimiento.

KEY WORDS

Research, artistic practice, phd thesis, exhibit, knowledge.

\section{RESUMEN}

La investigación en artes es un tema de gran actualidad y discusión ante el cual, no trataré de proponer un nuevo modelo aquí, pero si revisar algunas posturas que existen en torno a ella, precisando la metodología a seguir en el desarrollo de mi presente investigación. En Bellas Artes se pueden realizar investigaciones empleando diversos métodos, según el tema y planteamiento propuesto. Podemos por ejemplo utilizar modelos semejantes a los de la Historia, basados en la lectura, ordenación y relación de datos. Podemos también abordar estudios en los que el desarrollo conceptual se apoya en la producción, estableciendo un proceso de retroalimentación. Este último modelo se propone en la actualidad como el método específico de las Bellas Artes y es el que está generando gran cantidad de trabajo crítico. Mi tesis doctoral se asienta metodológicamente en él, en las práctices-based research, es decir, la articulación entre prácticas artísticas y los formatos de investigación académica operando de la mano teoría y práctica. Esto implica que a la vez que investigo en diversos textos, imágenes, videos, voy desarrollando mi propia obra que es enlazada a la investigación como una suerte de "estudio de campo" de las tesis en ciencias sociales, que es homologable al caso de las artes aunque de otra manera, ya que, con mi obra no pretendo ilustrar lo que voy escribiendo, ni corroborar una posible hipótesis, sino que me refiero a un medio de traspaso de ideas que es la obra y las imágenes con que estudio y trabajo. Y es que la producción artística es en sí misma una parte fundamental del proceso de investigación y la obra una manera de poder mostrar el resultado de ella dando respuesta al problema inicial, pero creando también permanentemente, nuevas definiciones del problema a través de la práctica artística.

\section{ABSTRACT}

Research in arts is a topic of a great interest and discussion towards which I will not try to expose here any new model but to review some of the existing positions related to it. I will also specify the methodology to follow throughout the development of my current research.

When it comes to the research in Fine Arts, there are diverse methods that can be used depending on the subject and the approach proposed. For instance, we may use similar models as those employed in History research based on reading, classifying and establish relations between data. It is also possible to address these studies in which a conceptual development relies on the production, and the establishment of a feedback process.

The last model mentioned above is the one proposed nowadays as the specific one for Fine Arts which generates a great volume of reviews. My thesis is methodologically based on this model as well as on "practices-based research" which means the relationship between artistic practices and formats of academic research interlacing theory and practice.

This implies that I am researching using different writings, images and videos and at the same time I am developing my own project which is linked directly to the research. In this case with my work, I do not intend to illustrate what I'm writing or corroborate a possible hypothesis, but I mean a way of transferring ideas between the art work and images that study and work. In fact the artistic production itself is an essential part of the research process. On the other hand my work is a way of delivering a response to the initial problem exposed in the beginning by creating permanently new definitions of the problem throughout the artistic exercise. 


\section{INTRODUCCIÓN}

La investigación en artes es actualmente el gran tema de debate dentro de la academia (aunque también en ocasiones, fuera de ella) puesto que plantea varias interrogantes aún indefinidas especialmente al embarcarse en un proyecto tan ambicioso como una tesis doctoral. Hoy se propone como método específico de las artes las llamadas práctices-based research o "práctica artística como investigación", es decir, la articulación entre teoría y práctica retroalimentándose cada una hacia ambos polos. Ante esta discusión no intento proponer un nuevo modelo aquí pero, si quisiera revisar algunas posturas que existen en torno a ella precisando finalmente la metodología a seguir en el desarrollo de mi tesis doctoral, una tesis realizada por una artista visual que entiende la creación artística como investigación.

“Pero ¿qué es la investigación artística hoy? En la actualidad, nadie parece saber la respuesta a esta pregunta. Se trata la investigación artística como una de esas múltiples prácticas que se definen por su indefinición, en un estado de fluctuación permanente, carentes de coherencia e identidad. Pero, ¿y si esta concepción fuera de hecho engañosa? ¿Y si en realidad supiéramos más sobre la investigación artística de lo que pensamos?"1
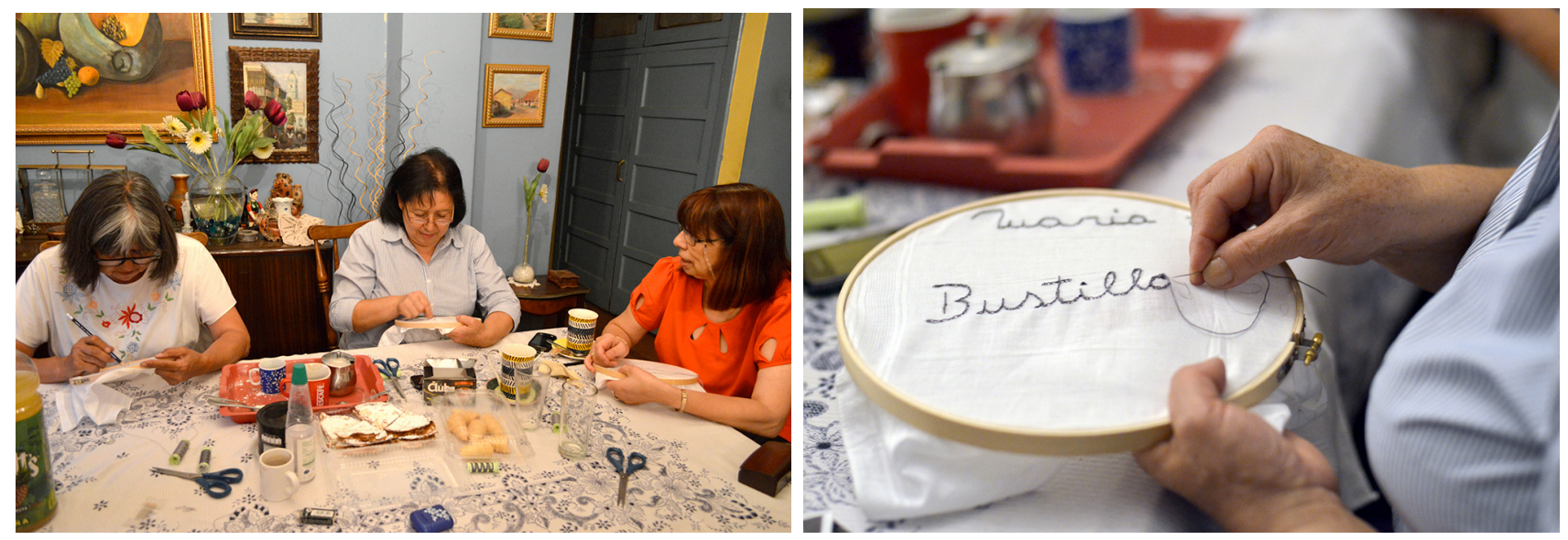

1- Detalles de la obra "Hilos de Ausencia: Genealogías y Discontinuidades". 2014. Viviana Silva @

\section{MOSTRAR, INTERROGAR, DECONSTRUIR EL MUNDO.}

La práctica artística como investigación implica que a la vez que investigo a la manera clásica, voy desarrollando mi propia obra como medio de traspaso de ideas, como un transmisor de conocimientos que es la obra y las imágenes con que estudio y trabajo. Y es que la producción artística es en sí misma una parte fundamental, siendo la obra, una manera de poder "mostrar" el resultado de ella dando respuesta al problema inicial pero también, creando permanentemente nuevas definiciones del problema a través de la práctica. Problema que en todo caso va siempre reformulándose en el recorrido mismo. Por consiguiente, es tanto con mi práctica artística como con el escrito que "expongo" mi investigación. ${ }^{2}$ Sin embargo parece ser, que en el mundo académico tradicional el trabajo artístico no se reconoce como generador de conocimiento y mucho menos la creación como investigación, lo que deriva en el problema del montaje, el cómo presentar y articular nuestras investigaciones para que encajen y cómo articular el texto como montaje. $^{3}$

\footnotetext{
${ }^{1}$ STEYERL, Hito. ¿Una estética de la resistencia? La investigación artística como disciplina y conflicto. [en línea] 2010 [Consulta: 6-10${ }^{2}$ Cabe esclarecer que el concepto de exposición/exponer responde a un doble significado involucrado en esta discusión metodológica. En la escritura académica es sinónimo de explicar, referir, plantear, describir o incluso razonar, mientras que en el mundo del arte significa exhibir, representar o mostrar. "El concepto de exposición de la investigación conecta este doble significado de la palabra exponer con la intención de reconsiderar el escrito académico y replantearlo como escritura que está entre la práctica y la teoría, así como también entre modos de trabajo académicos y no-académicos" en definitiva, aunaría elementos artísticos y estéticos (no siempre lingüísticos) relacionados con las artes visuales y con el texto, que desde la academia se nos exige a los investigadores. La cita es de GRANDE, Helena. "Exposición de la investigación artística. Una aproximación al Journal for Artistic Research y el Research Catalogue". En: BLASCO, S.(ed.) Investigación Artística y Universidad: Materiales para un debate. Madrid: Ediciones Asimétricas, 2013.p.89

${ }^{3}$ Sobre ello, Aurora Fernández plantea que si la exposición en los espacios de arte se basa en el montaje, también lo hace la forma de escritura-como-montaje, la cual propone como estrategia que podría ayudar a resolver algunos problemas en torno al trabajo escrito en la investigación artística académica. Es, en la escritura como montaje que estaría la clave, ya que aunaría elementos artísticos y estéticos (no siempre lingüísticos) relacionados con las artes visuales, con el texto, que desde la academia se nos exige a los investigadores. FERNÁNDEZ POLANCO, A. "Escribir desde el montaje. Otra forma de exponer". En: BLASCO, S.(ed.) Investigación Artística y Universidad: Materiales para un debate. Madrid: Ediciones Asimétricas, 2013. p.106
} 
Si bien, hace muchos años que los/as creadores/as cada vez más ajenos a los modelos de la autonomía del arte y del formalismo crean nuevas "representaciones" concebidas como producción de conocimiento, apelando a la innovación y análisis crítico-teórico, y considerando que los nexos entre investigación y creación están relacionados con la propia evolución del arte contemporáneo que tiende a la desmaterialización de la obra acercando el trabajo del artista a la especulación teórica, la idea de "creación artística" se ha vuelto ideológicamente insostenible. Del artista ya no se valora el talento ni la creatividad según el modelo romántico heredado por las vanguardias, sino que la reflexión y análisis teórico tras la pieza, ${ }^{4}$ la intelectualidad. "La función del artista ya no consiste tanto en el juego de la invención como en el de la interrogación de su propio 'mundo', en la crítica o la deconstrucción", 5 residiendo su poder de significar en la ambigüedad del lenguaje que utiliza, que expande su sentido a territorios mucho mayores que los de un texto sólo que necesita ser leído y para ello requiere de cierta formación, de una atención diferente por parte del lector-espectador, especialmente desde que el arte ha incorporado el concepto como elemento fundamental de su arquitectura, siendo las referencias a las ideas de otros, a la obra de otros, a los textos de otros, implícitas pero presentes.

Una de las cuestiones esenciales entonces, es llegar primeramente a un acuerdo sobre si el arte produce conocimiento o no, y si lo puede transmitir. Para Judith Siegmund, el arte es definido cada vez más como un modo de producción de saber, el cual debe entenderse como un indicador de transformaciones que en parte se producen en el arte mismo pero que también van más allá de éste. A su juicio, el concepto de saber de las artes debe ser determinado como un saber práctico, como una modalidad particular de aproximación al mundo de tipo práctico-cognitivo no universal. "El arte como producción de saber debe entenderse como la creación de modalidades concretas de aproximación al mundo, a sus contextos y objetos, lo que significa que algo oculto ha sido revelado, que algo que había pasado desapercibido accede a un lugar central y no que algo es creado en un sentido vanguardista. Muchas y muchos artistas parecen entender el saber más como un conocimiento que se puede reformular en proposiciones antes que como la capacidad de exponer lo sabido como una argumentación lingüística." ${ }^{\prime 6}$ Aquí radica una distancia que separa la investigación artística de la científica y que es sustancial. El rigor, entiéndase rigor científico versus lo artístico que ocurre en un terreno más híbrido, flexible y que se acerca a su vez al ensayo, lugar desde el que hacemos proposiciones. "El ensayo no obedece a la regla del juego de la ciencia y de la teoría organizadas según la cual, el orden de las cosas es el mismo orden de las ideas [...] El ensayo no apunta a una construcción cerrada, deductiva o inductiva. Se yergue sobre todo contra la doctrina [...] En el ensayo el pensamiento se libera de la idea tradicional de verdad. Con ello suspende al mismo tiempo el concepto tradicional de método." ${ }^{7}$ Tiene sin embargo, un valor heurístico adecuado para el arte ya que en la investigación artística ocurre algo similar. Hablar de hipótesis por ejemplo, que en el ámbito científico es algo unívoco y preciso implicando metodologías y sistemas de evaluación claramente definidos en el ámbito artístico se vuelve extraño, lejano y ambiguo.

“¿Y qué otra cosa es una hipótesis sino un error asumido como prótesis? La prótesis como lo oblicuo, el método sinuoso, en el que el error actúa como rodeo, magia propiciatoria, encantamiento y palanca". ${ }^{8}$

Hablar de hipótesis en la tesis para mi es peregrino, pues no realizo una investigación en la cual una serie de supuestos e interrogantes iniciales comprueben o nieguen finalmente algo. Más bien, trabajo desde el planteamiento de unos cuantos objetivos a analizar que construyen un discurso en un sentido determinado pero que son sólo proposiciones. Y es que el arte no es estrictamente sumativo. Se niega constantemente a sí mismo - o puede hacerlo- y no tiene la finalidad de llegar a algo cerrado ni sentencioso. Tanto en el arte como en el ensayo, "Ios conceptos no constituyen un continuo operativo, el pensamiento no procede linealmente y en un solo sentido, sino que los momentos se entretejen como hilos de una tapicería. La fecundidad del pensamiento depende de la densidad de esa intrincación." ${ }^{9}$

En mi tesis, he desarrollado como parte de mi investigación una obra que versa sobre la Operación Colombo, operativo montado por la dictadura militar de Pinochet junto a los medios de comunicación, en el que desparecieron 119 personas opositoras al régimen. Esta obra, que lleva por titulo Hilos de Ausencia: Genealogías y Discontinuidades, ${ }^{10}$ de producción textil que junto a la fotografía y el

\footnotetext{
${ }^{4}$ De hecho esta idea del artista intelectual es realmente tan antigua como el propio Leonardo Da Vinci quien ya en sus años planteaba que el artista es un ser que piensa y que la pintura no es una práctica intuitiva, emotiva y expresiva como dirían los románticos, sino una creación intelectual. Lo que pasa es que aún en la actualidad sigue existiendo esa otra creencia, idealista, del arte como inspiración divina. Sobre este tema ver VAN ALPHEN, Ernst. "¿Qué Historia, la Historia de Quién, Historia con Qué Propósito?: Nociones de Historia en Historia del Arte y Estudios de Cultura Visual". Revista de Estudios Visuales. [en línea] No3, 2006 [Consulta: 8-10-2013] Disponible en: http://www.estudiosvisuales.net/revista/pdf/num3/alphen.pdf

${ }^{5}$ DÍAZ CUYÁS, José. "Mostrar y demostrar: arte e investigación". En: Seminario INTER/MULTI/CROSS/TRANS. El territorio incierto de la teoría de arte en la época del capitalismo académico. [en línea] 3 y 4 Diciembre de 2010. Montehermoso, Victoria-Gasteiz. [Consulta: 1711-2014] Disponible en: http://www.arteinvestigacion.net/2012/04/mostrar-y-demostrar-arte-e.html

${ }^{6}$ Siegmund es artista y filósofa, académica de la Universität der Künste de Berlín. SIEGMUND, Judith. ¿Saber versus creatividad? Sobre las modalidades de descripción del arte y su relación con los contextos económicos y sociales. [en línea] 2011 [Consulta: 6-10-2014] Disponible en: http://eipcp.net/transversal/0311/siegmund/es

7 ADORNO, Theodor. "El ensayo como forma". En: Notas de Literatura. Barcelona: Ariel, 1962. pp.19-21

${ }^{8}$ LOOTZ, Eva. "Pequeño teatro de derivas". En: Lo visible es un metal inestable. Madrid: Árdora Ediciones, 2007, p.123

${ }^{9}$ ADORNO, op. cit., p.23

${ }^{10}$ La obra, además de su formato de exhibición cuenta con una página web donde he volcado toda la información relativa al proyecto, las imágenes del proceso y de la obra final, los videos elaborados como parte de la obra, textos, etc. todo ello como dispositivo de la obra y como otra forma de exposición. La web es www.hilosdeausencia.com
} 
audiovisual utilizo como documento, da cuenta de la desaparición, de la memoria de mi país y de una parte de la Historia -con mayúsculas - que ha sido silenciada, siendo una obra que tras una investigación en torno a las historias de este caso, los archivos que quedan, más la recogida de testimonios de familiares y amigos/as, la implicación conjunta con ellos/as en el acto de bordar sus nombres y su puesta en escena final permite, traer a la memoria este acontecimiento y poderlo visibilizar.
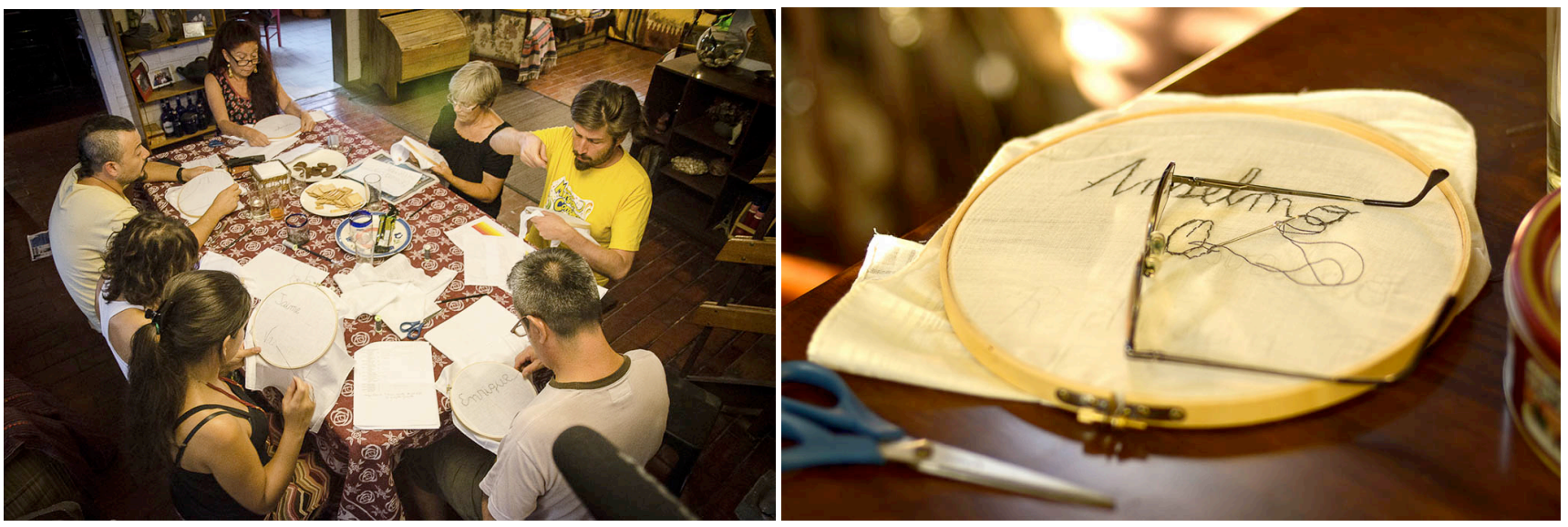

2- Detalles de la obra "Hilos de Ausencia: Genealogías y Discontinuidades". 2014 ㄷ Viviana Silva

Pero, ¿puede la imagen entablar un discurso? ¿Puede hacerlo Hilos de Ausencia?

Víctor Burgin plantea que si bien la imagen puede sugerir argumentos, no tiene la capacidad de desarrollarlos adecuadamente. En respuesta a su texto Desmond Bell replica, que Burgin reproduce las divisiones entre trabajo intelectual y manual, pero coincide en la necesidad de mantener un cuerpo de escritura crítica, al menos dentro del doctorado que aunque no sea un argumento cerrado, tenga un sentido dado por una correcta articulación del discurso. ${ }^{11}$ Para Bell, el programa de investigación y evaluación del doctorado tiene que ser negociado caso a caso con la condición de que todos/as los/as aceptados/as en un doctorado de práctica artística deben producir tanto un cuerpo de escritura crítica contextualizada de su trabajo, como un cuerpo de práctica artística documentada. Deben asimismo demostrar que el cuerpo de trabajo está motivado por un diseño de investigación con una metodología práctica de estudio (en el sentido más amplio), que su contexto de investigación es importante y que hay una estrategia clara para avanzar en sus indagaciones. No se trata entonces de una noción anticuada exigir una disertación, un texto de una longitud de palabras estipulado, ni es para él una resistencia romántica exigir que los candidatos sean de práctica libre para presentar un trabajo creativo.

Ahora bien, la creación artística no ha tenido como finalidad o función investigar; es decir, contribuir a un conocimiento razonable del mundo en comparación con el resto de disciplinas universitarias que si han hecho suyas estas tareas, lo que no implica que el arte no genere conocimiento. Para José Díaz Cuyás, "el problema es que así como se puede decir sin violentar su realidad histórica que el arte produce conocimiento, resulta muy problemático afirmar que ese conocimiento sea del mismo orden que el de un saber razonable (es decir, que pueda tener un valor demostrativo, que dependa de su eficacia o que venga a corroborar o falsear la validez de una hipótesis)" ${ }^{12}$ Esta es una diferencia fundamental. Cuando hablamos de conocimiento, no excluimos ningún modo de experiencia, sin embargo, cuando adjudicamos al arte un modo de conocimiento previsto como un saber asentado en un método razonable demostrativo, "eliminamos de un plumazo toda posibilidad de mediación artística, en especial el carácter radical y necesariamente procesual de la experiencia que le es propia: a saber, el hecho de que su sentido no descansa en unos supuestos predicados artísticos sino en aquello que ocurra en el proceso de su propio acontecer, en aquello que toda obra sólo puede mostrar o dar a conocer en acto.[...] Una obra puede interpretarse como si fuera un discurso, pero de ello no cabe deducir que pueda ser reducible a enunciados discursivos. Sea el individuo en cuestión consciente de ello o no, esta particularidad irreductible se debe a que en toda obra se quiebra la relación automática y codificada entre signo y significado."13 Hilos de Ausencia es una obra que como tal, accede por otros medios al espectador; sin embargo, creo que permite mostrar, dar a ver algo y generar con ello nuevos conocimientos en torno a este caso

\footnotetext{
${ }^{11}$ Burgin para su planteamiento se apoya en Derrida quien argumenta con un ejemplo de una de sus clases, que no rechaza a la imagen en la producción de un discurso por ser imagen sino porque no elabora de manera precisa un discurso ni lo sustituye suficientemente. Para una mirada más exhaustiva sobre este argumento y conocer el ejemplo de Derrida ver BURGIN, Víctor. "Reflexiones sobre grado de "investigación" en los departamentos de artes visuales." En: Journal of Media Practice 7. №2, 2006. pp.101-108. En contraparte, los argumentos de Bell se pueden ver en BELL, Desmond. "Is there a doctor in the house? A riposte to Victor Burgin on practice-based arts and audiovisual research". En: Journal of Media Practice 9. №2, 2008. pp.171-177. Traducción personal.

${ }^{12}$ DÍAZ CUYÁS, op. cit.

${ }^{13}$ DÍAZ CUYÁS, op. cit.
} 
particular y en torno a las imágenes del país que nos han ido construyendo. Reflexionando sobre ello pues algo que había pasado desapercibido ha accedido (dentro de sus posibilidades y alcances) a un lugar central, aunque sea a través de otros modos de codificación.

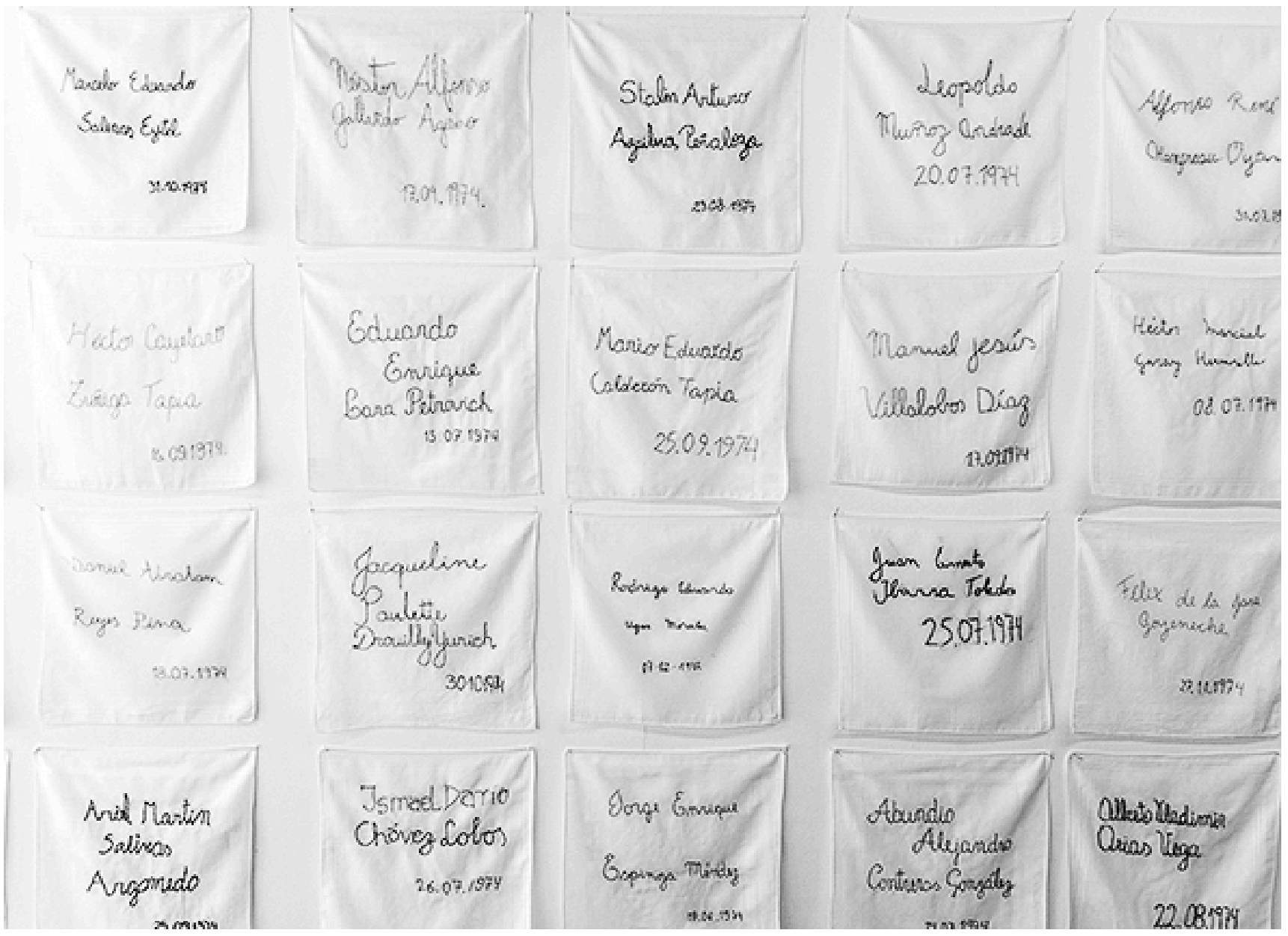

3- "Hilos de Ausencia: Genealogías y Discontinuidades". 2014 (C) Viviana Silva

\section{UN PROBLEMA DE DISTANCIAS.}

Borgdorff de la Escuela de Artes de Amsterdam es en torno a este tema algo más "radical". Para él "investigar en arte se refiere a la investigación que no asume la separación de sujeto y objeto, y no contempla ninguna distancia entre el investigador y la práctica artística, ya que ésta es, en sí, un componente esencial tanto del proceso de investigación como de los resultados de la investigación" ${ }^{14}$ Esta unión se basa en la idea de que no existe separación entre teoría y práctica en las artes, después de todo, no hay prácticas artísticas que no estén saturadas de experiencias, historias y creencias, y a la inversa, no hay un acceso teórico o interpretación de la práctica artística que no determine parcialmente esa práctica tanto en su proceso como en su resultado final. Conceptos y teorías, experiencias y convicciones están entrelazados y en parte por esta razón, el arte es reflexivo. De ahí que la investigación en artes trate de articular parte de este conocimiento, expresado en el proceso creativo y en el objeto artístico mismo. En esta línea el Proyecto Grid Spinoza ${ }^{15}$ se refiere al término investigación artística para describir el proceso artístico en sí mismo, para

\footnotetext{
${ }^{14}$ En 1933 Christopher Frayling bajo el título de "Investigación en arte y diseño" introdujo una distinción entre tipos de investigación en las artes a los que muchos se han referido desde entonces. Frayling diferenciaba entre: "investigación dentro del arte", "investigación para el arte" e "investigación a través del arte". Henk Borgdorff posteriormente utiliza también esta tricotomía aunque con un enfoque ligeramente diferente. Él distingue entre: (a) investigación sobre las artes, (b) investigación para las artes y (c) investigación en las artes. Este último término sería el vinculado a las práctices-based research y a la metodología de mi tesis doctoral. Para saber más sobre ello ver: BORGDORFF, Henk. El debate sobre la investigación en las artes. Amsterdam School of the Arts, 2006.

${ }^{15}$ Proyecto que explora los procesos, metodologías y dinámicas de la investigación artística y científica. Para saber más sobre él: Proyecto Grid-Spinoza: ¿De qué hablamos cuando hablamos de investigación artística? [en línea].[s.f.] [Consulta: 3-10-2013] Disponible en: http://www.gridspinoza.net/es/node/82
} 
apuntar una auténtica disciplina que incluye además de la creación de una obra, una fase de investigación previa que genera cierto conocimiento susceptible de ser transferido más allá de la experiencia estética como, el diseño de un prototipo a partir de la experimentación tecnológica; la elaboración de nuevos sistemas de visualización de datos, etc. Investigaciones que se realizan desde la transversalidad y tomando prestadas de otras disciplinas muchos de sus métodos y herramientas lo que amplía los horizontes de la práctica artística y permite asimismo, grados de experimentación que no pueden tener lugar en la rigidez de las otras disciplinas. Sin embargo, hay quienes plantean que el hecho de que los artistas realicen investigaciones exhaustivas previas a una obra no es hablar de investigación artística, ni tampoco acercarse desde el arte al lenguaje de las ciencias sociales ${ }^{16}$. Como vemos, la discusión es abierta y aunque existen voces que defienden directa o indirectamente posiciones contrarias en torno a si la obra puede ser considerada investigación o no, y si puede generar conocimiento o no, el problema en todo caso es, que para que la investigación artística sea reconocida de manera "oficial", implica cumplir con los requisitos que han sido definidos desde la aparición de las Universidades y que han dado lugar a una serie de normas que regulan los procesos y la presentación de resultados financiándose y evaluándose según los marcos ideológicos del I+D -innovación y desarrollo. El mundo académico es riguroso y protocolar puesto que la normalización conduce a la universalidad, en cambio el arte no admite ser definido en criterios de disciplina, porque la disciplina normaliza y regula, lo que no implica que el arte no produzca un saber del mismo modo que la ciencia. Lo que pasa es que la forma de exponer ese conocimiento es diferente. "El producir del arte se basa en la acción de mostrar, mientras que el producir tecnocientífico se sustenta en la efectividad y la demostración" ${ }^{17} Y$ es que "mostrar significa abrir de un tajo el mundo". ${ }^{18}$

Así pues, gran parte de la animadversión contra la investigación artística proviene de una sensación de amenaza por la disolución de estas fronteras y es éste quizá el motivo por el cual con frecuencia en lo cotidiano, se niega que la investigación artística sea arte o que el arte sea investigación. En este sentido entiendo que para muchos es incómodo que la investigación artística obedezca a la necesidad de adaptarse a estructuras cada vez más homogéneas y rígidas del sistema de educación superior en el que domina la investigación científica como modelo a seguir, y entiendo también la incertidumbre que genera realizar una Tesis Doctoral en Bellas Artes ya que yo misma lo estoy viviendo. Sin embargo, quizás en cierta medida, esta unificación en la academia lleva o llevará a que el arte se asocie al conocimiento y así se revalorice como debió ocurrir hace tiempo. "La cuestión, en principio irresoluble, parece ser esta: ¿cómo puede demostrar el arte que aquello que sólo alcanza a mostrar - tal como le corresponde- sirve efectivamente a la nueva teleología de la Investigación —entendida como el sumando de la Innovación y el Desarrollo-?"19 Y si ¿queremos servir a ello?

\section{CONCLUSIONES}

Desde mi punto de vista, la investigación artística no solo evidencia el íntimo vínculo entre teoría y práctica sino que también encarna la promesa de un camino diferente, en un sentido metodológico, que la separa de la academia predominante, permitiéndonos a los/as artistas acceder a los/as espectadores por otras vías de comunicación. Es por ello, que disfruto tanto realizando obra, implicada en esta conjunción única, envuelta en el hecho de investigar y mostrar. La práctica artística, ya sea el objeto artístico como el proceso creativo, contiene un conocimiento implícito y silencioso que puede ser mostrado por medios de experimentación e interpretación diferentes a los tradicionales. Ahora bien, para que la práctica artística pueda ser calificada como investigación debe tener como uno de sus propósitos aumentar nuestro conocimiento y comprensión, debe contener una investigación original en y a través de objetos artísticos, debe tener tras de sí por tanto, un proceso intelectual.

En mi caso, la práctica artística es fundamental y es imposible de separar en mi tesis doctoral. Quizá como "deformación" profesional porque soy artista, pero es que con la práctica pienso, y con ella intento generar alguna cosa más. Un saber podemos decir, que es expuesto y recepcionado de otra manera pero que está ahí, presente en la obra, como creo está sucediendo con Hilos de Ausencia donde está latente este modo de traspaso de información. Ahora bien sé también que dentro de la academia, lugar en que se realizan los Doctorados en Bellas Artes por tanto la tesis, y lugar en que actualmente me encuentro, debe haber un texto, y por ello mi tesis se desarrolla en medio de ambas cuestiones, o más bien, con ambas cuestiones. Por tanto me parece inconcebible separarlas pues sin su relación dialógica no podrían existir.

El alcance de estos debates es complejo, abierto y con variadas aristas. El camino la verdad es algo difuso y bastante incierto. No sé bien que sucederá en este viaje teórico-visual en el que me he embarcado llamado investigación artística, pero sea lo que sea, seguro será para mejor. Y es que "el arte no aparece como repertorio de respuestas, ni siquiera como gesto de buscarlas. Es más bien, el lugar donde las preguntas y las dudas se traducen y retraducen, oyen su resonar." ${ }^{20}$

\footnotetext{
${ }^{16}$ Es lo que plantea por ejemplo Chus Martínez en su texto ¿Qué queremos decir con Investigación Artística?, donde indica que la investigación artística es muy connotada pero pobremente definida, y que el hecho de que los artistas realicen investigaciones exhaustivas previas a una obra no es hablar de investigación artística. Hay que subrayar que en el momento de la publicación de este texto, Chus era conservadora jefe del MACBA y que por tanto su discurso no se plantea desde la academia a diferencia de los otros debates propuestos a lo largo de este texto. MARTíNEZ, Chus. "Felicidad Clandestina. ¿Qué queremos decir con Investigación Artística?”. Revista ÍNDEX. Investigación artística, pensamiento y educación. Departamento de Publicaciones del MACBA. 2010, №0. pp.10-13

${ }^{17}$ DÍAZ CUYÁS, op. cit.

${ }^{18}$ LOOTZ, op. cit., pp.21-26

${ }^{19}$ DÍAZ CUYÁS, op. cit.

${ }^{20}$ GARCÍA CANCLINI, Néstor. La sociedad sin relato. Antropología y estética de la inminencia. Buenos Aires: Katz Editores, 2010. p.163
} 


\section{FUENTES REFERENCIALES.}

ADORNO, Theodor. "El ensayo como forma”. En: Notas de Literatura. Barcelona: Ariel, 1962.

BELL, Desmond. "Is there a doctor in the house? A riposte to Victor Burgin on practice-based arts and audiovisual research". En: Journal of Media Practice 9. №2, 2008. pp.171-177

BORGDORFF, Henk. El debate sobre la investigación en las artes. Amsterdam School of the Arts, 2006.

BURGIN, Víctor. "Reflexiones sobre grado de "investigación” en los departamentos de artes visuales." En: Journal of Media Practice 7. №2, 2006. pp.101-108

DÍAZ CUYÁS, José. "Mostrar y demostrar: arte e investigación”. En: Seminario INTER/MULTI/CROSS/TRANS. El territorio incierto de la teoría de arte en la época del capitalismo académico. [en línea] 3 y 4 Diciembre de 2010. Montehermoso, Victoria-Gasteiz. [Consulta: 17-11-2014] Disponible en: http://www.arteinvestigacion.net/2012/04/mostrar-y-demostrar-arte-e.html

FERNÁNDEZ POLANCO, Aurora. "Escribir desde el montaje. Otra forma de exponer". En: BLASCO, S.(ed.) Investigación Artística y Universidad: Materiales para un debate. Madrid: Ediciones Asimétricas, 2013.

GARCÍA CANCLINI, Néstor. La sociedad sin relato. Antropología y estética de la inminencia. Buenos Aires: Katz Editores, 2010.

GRANDE, Helena. "Exposición de la investigación artística. Una aproximación al Journal for Artistic Research y el Research Catalogue". En: BLASCO, S.(ed.) Investigación Artística y Universidad: Materiales para un debate. Madrid: Ediciones Asimétricas, 2013.

LOOTZ, Eva. "Pequeño teatro de derivas”. En: Lo visible es un metal inestable. Madrid: Árdora Ediciones, 2007.

MARTíNEZ, Chus. “Felicidad Clandestina. ¿Qué queremos decir con Investigación Artística?”. Revista ÍNDE . Investigación artística, pensamiento y educación. Departamento de Publicaciones del MACBA. 2010, №0. pp.10-13

MUNÁRRIZ, Jaime. Investigación y tesis doctoral en Bellas Artes, 2013. Documento orientativo para la realización de la Tesis Doctoral en Bellas Artes. Propuesta de marco que intenta aclarar algunos conceptos básicos que pueden resultar útiles al iniciar una tesis.

Proyecto Grid-Spinoza: ¿De qué hablamos cuando hablamos de investigación artística? [en línea].[s.f.] [Consulta: 3-10-2013]

Disponible en: http://www.gridspinoza.net/es/node/82

Seminario En torno a la investigación artística. Pensar y enseñar arte: entre la práctica y la especulación teórica. Barcelona: Museo de Arte Contemporáneo de Barcelona, MACBA.[en línea] Del 09 abr. 2010 al 10 abr. 2010. [Consulta: 5-2-2013] Disponible en: http://www.macba.cat/es/en-torno-a-la-investigacion-artistica

SIEGMUND, Judith. ¿Saber versus creatividad? Sobre las modalidades de descripción del arte y su relación con los contextos económicos y sociales. [en línea] 2011 [Consulta: 6-10-2014] Disponible en: http://eipcp.net/transversal/0311/siegmund/es

STEYERL, Hito. ¿¿Una estética de la resistencia? La investigación artística como disciplina y conflicto. [en línea] 2010 [Consulta: 6-102014] Disponible en: http://eipcp.net/transversal/0311/steyerl/es

VAN ALPHEN, Ernst. "¿Qué Historia, la Historia de Quién, Historia con Qué Propósito?: Nociones de Historia en Historia del Arte y Estudios de Cultura Visual". Revista de Estudios Visuales. [en línea] №3, 2006 [Consulta: 8-10-2013] Disponible en:

http://www.estudiosvisuales.net/revista/pdf/num3/alphen.pdf 